\title{
Chronic Cough as the Presenting Symptom of Eosinophilic Esophagitis
}

\author{
Victoria Shum ${ }^{1,2}$, Russell Hopp ${ }^{1, *}$, Hana Niebur $^{1}$ and Ashley Deschamp ${ }^{1}$ \\ 1 Children's Hospital and Medical Center, Department of Pediatrics, University of Nebraska Medical Center, \\ Omaha, NE 68114, USA; victoria.shum@CHKD.org (V.S.); hniebur@childrensomaha.org (H.N.); \\ adeschamp@childrensomaha.org (A.D.) \\ 2 Children's Hospital of the Kings Daughters, Department of Pediatrics, Eastern Virginia Medical School in \\ Norfolk, Norfolk, VA 23507, USA \\ * Correspondence: rhopp@childrensomaha.org
}

Citation: Shum, V.; Hopp, R.; Niebur, H.; Deschamp, A. Chronic Cough as the Presenting Symptom of Eosinophilic Esophagitis. Allergies 2021, 1, 176-180. https://doi.org/ 10.3390/allergies1030016

Academic Editor: Pierre Rougé

Received: 28 July 2021

Accepted: 24 August 2021

Published: 1 September 2021

Publisher's Note: MDPI stays neutral with regard to jurisdictional claims in published maps and institutional affiliations.

Copyright: (c) 2021 by the authors. Licensee MDPI, Basel, Switzerland. This article is an open access article distributed under the terms and conditions of the Creative Commons Attribution (CC BY) license (https:/ / creativecommons.org/licenses/by/ $4.0 /)$.

\begin{abstract}
A 14-year-old male initially presented to the Emergency Department (ED) for a chronic, persistent cough and chest pain with concurrent history of asthma and gastroesophageal reflux disease (GERD). He had been trialed on several medications before this visit for cough, without resolution of symptoms. Despite seeing several specialists after this ED visit and being evaluated for infectious causes and other pulmonary issues, he was eventually found to have eosinophilic esophagitis (EoE). It is not often that EoE is suspected based on cough alone, but with other GERD-like symptoms EoE should be considered.
\end{abstract}

Keywords: case report; eosinophilic esophagitis; cough; gastroesophageal reflux

\section{Introduction}

Chronic cough can have a long differential diagnosis. Asthma itself can be a cause. We present a male with chronic asthma who developed a new chronic cough.

\section{Case Report}

A 14-year-old white male presented to the Emergency Department (ED) (May 2020) with 8 weeks of persistent cough, chest pain, and difficulty swallowing. He initially was evaluated at several outside facilities (over the 8 weeks before the ED visit) where he had tested negative for COVID-19 and started prednisone, azithromycin (possible pertussis), and codeine cough syrup, and was given a steroid shot (Decadron). He had three previously negative chest X-rays. He works with domestic ducks. He also had a laryngoscopy and was started on esomeprazole (Nexium) and gabapentin for reflux and remained on it for 6 weeks before the ED visit. In addition, he was on cetirizine for seasonal allergies, Symbicort (budeonide/and formoterol fumarate dihydrate combination), montelukast, and albuterol for asthma, clarithromycin (Biaxin as a 2nd round antibiotic for presumed pertussis). Other medications he had tried were benzonatate (Tessalon Perles) and omeprazole (Prilosec), neither of which helped.

In the ED, he pointed to the center of his chest when asked to localize the pain and stated the pain was constant. When he coughed, he felt "a shock" to his body and his hands became numb. The cough was disruptive to his sleep. He denied having fever, congestion, rhinorrhea, nausea, vomiting, or diarrhea. His mother voiced concern because of a recent paternal family member who had cardiac issues and died early at 27 years old.

His past medical history includes asthma, diagnosed when he was 7 years old, allergy to dust mites, and seasonal allergies. He said this cough was different than his infrequent asthma cough as the new cough was becoming more frequent. Albuterol helped minimally. His sister had asthma. His past surgical history includes adenoidectomy, tonsillectomy, and tympanostomy with tube insertion. 
His physical exam was unremarkable except for chest tenderness that was not reproduceable on palpation. The rest of the review of systems and physical exam were otherwise negative.

Electrocardiogram and chest X-ray were normal. Pseudoephedrine was given in the $\mathrm{ED}$ and he was sent home with plans for a pulmonology follow up in one week.

He saw Pulmonology via Telehealth (due to living 100 miles from the Pediatric Specialist and limited in-person visits due to COVID precautions at the specialty outpatient clinic). It was noted that he choked when he ate but did not remember aspirating on any food or objects. Review of systems at that appointment was positive for chest pain, cough, heart burn, extremity numbness, and allergies. At that time the differential diagnosis included infection, asthma, gastroesophageal reflux, allergies, foreign body aspiration, and habit cough. At an in-person follow up clinic visit to the same specialist, his spirometry showed normal lung function and no significant response to bronchodilation. His fractional exhaled nitric oxide (FeNO) was $25 \mathrm{ppb}$ (normal range for age $<25 \mathrm{ppb}$ ). He was instructed to continue current medications with a presumed diagnosis of habit cough.

However, due to the persistence of his cough he was then scheduled for a bronchoscopy (4 months after the ER visit). Upper airway inflammation was noted with cobblestoning. The lavage culture grew a small amount of penicillium genus, considered to be a contaminate, and he was put on two weeks of fluconazole. Bronchoalveolar lavage fluid showed a lipid index of 4 , not indicating microaspiration. The lavage cell count was mixed neutrophils and mononuclear cells, without eosinophils. The cough improved with fluconazole but was still present and worsened again a month later. Allergy was consulted.

He saw Allergy via Telehealth 7 months after the cough had started. It was at this time that the patient revealed he would usually eat meals in his room instead of with the family and he feels food get stuck when eating, especially meat. He also had modified his eating behavior, with small portions and longer chewing. He maintained a proton pump inhibitor, received a TB skin test (negative), and was scheduled with an esophagogastroduodenoscopy (EGD) in 3 weeks (with COVID limitations for numbers of surgical suite patients).

The endoscopy showed four eosinophils on a high-powered field in the proximal esophagus and 25 in the distal esophagus with furrowing in three out of four quadrants and mild exudates on macroscopic view (Figure 1). He was prescribed $1 \mathrm{mg}$ of budesonide swallowed BID as a slurry with Splenda with instruction to rescope in 6-8 weeks.

Three weeks into therapy, his mother was called for follow up and said the cough was $80 \%$ better. The scope 6 weeks after starting budesonide showed total resolution of esophageal eosinophilia and a normal macroscopic examination. His cough remained improved.

On a Telehealth visit one year after the start of his cough, he was on budesonide slurry at bedtime. He had stopped his Symbicort (budesonide and formoterol fumarate dihydrate combination). A subsequent in-person visit revealed a normal pulmonary function without bronchodilatation (off all asthma therapy). His cough was resolved totally. 


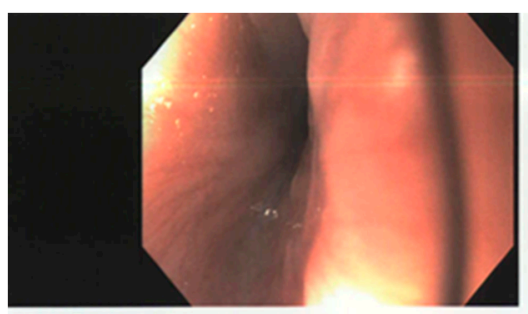

PROXIMAL ESOPHAGUS

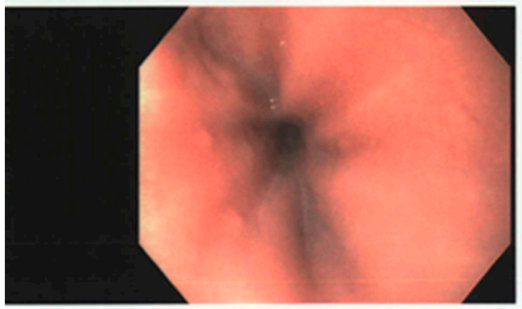

DISTAL ESOPHAGUS

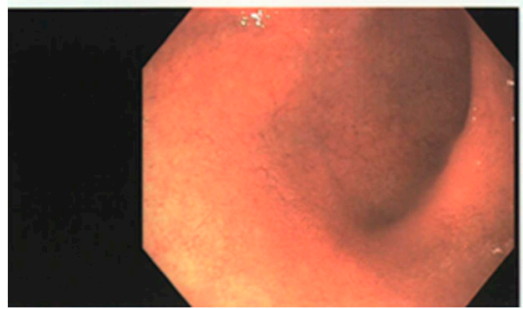

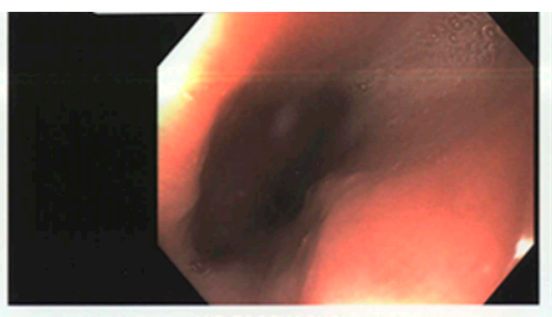

MID ESOPHAGUS

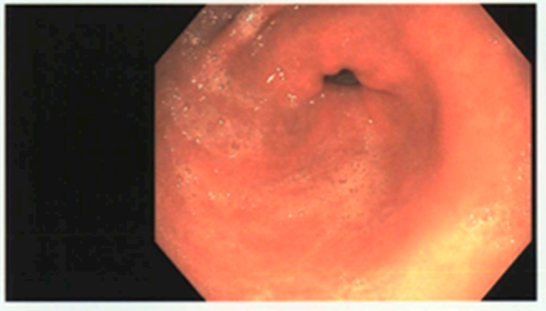

STOMACH: ANTRUM

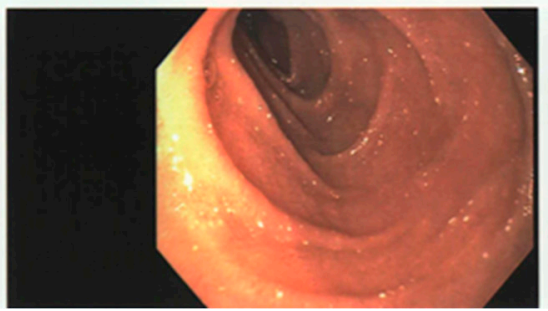

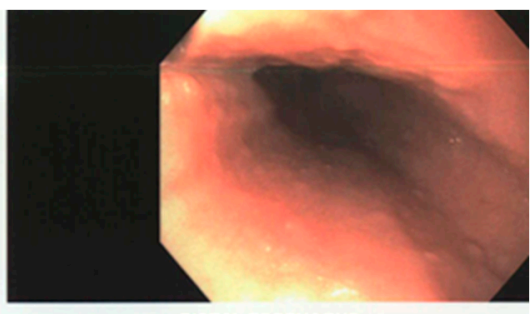

DISTAL ESOPHAGUS

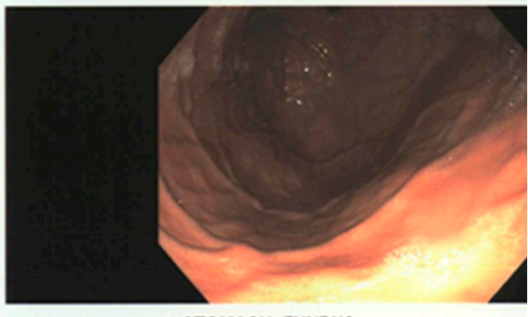

STOMACH: FUNOUS

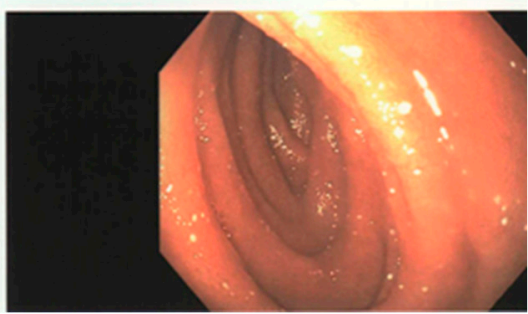

Figure 1. Visualized endoscopy findings at first EGD.

\section{Discussion}

Eosinophilic esophagitis (EoE) has had an evolution of definitions over the years. The current criteria for diagnosis include symptoms of esophageal dysfunction with 15 or more eosinophils per high-powered field on esophageal biopsy [1]. The most common presentation of EoE in adolescents includes esophageal dysphagia, food impaction, heartburn, and non-cardiac chest pain [2]. Our patient's primary complaint was of cough with a past medical history of GERD and asthma. Dysphagia was not a symptom shared on initial presentation or even months into work up. Unknowingly, many of the typical symptoms of EoE were being concealed by compensatory behavioral changes such as chewing his food finely, cutting it up, and drinking lots of water at meals and was accepted as his normal. These behavior modifications are not uncommon and can be developed subconsciously [2-4]. For our patient, in addition to these behaviors, he also ate alone in his room and would hide any food he could not chew and spit it back out on his plate.

The most common presenting symptoms of EoE in children are reflux, emesis, abdominal pain, and in adolescents, dysphagia and food impaction [5]. Cough is an uncommon presentation of EoE but was the chief complaint for our patient. Evaluation of chronic cough in adolescents contains a long differential, including asthma, GERD, upper and lower respiratory tract infections, pertussis, post-nasal drip, aspiration, and psychogenic cough [6], while less common possibilities of tuberculosis, eosinophilic pneumonia, or eosinophilic granulomatosis with polyangiitis were excluded by chronicity, lack of pulmonary symptoms, and repeated normal chest X-rays. It is reasonable to rule these out in evaluation, as was achieved by the combination of PPI trial, antibiotics, chest X-rays, and adjusting asthma and seasonal allergy controls. When his cough did not persistently improve with extensive interventions, reevaluation of less common causes could have been considered earlier. A case report was written of a 2 year old with a dry cough for 6 months who was also suspected to have GERD but was unresponsive to a PPI and diagnosed with EoE [7]. Few other cases diagnose EoE with a primary complaint of chronic cough $[7,8]$. 
EoE is more common in males than females and in Caucasians than other races [9] Additionally, asthma and allergic rhinitis are common co-diseases with EoE [10,11].

Chronic cough in a patient with other risk factors, such as asthma and allergy, who fits the demographic risk of being a Caucasian male, should prompt consideration of eosinophilic esophagitis, a less common allergic disease. While GERD is a more common cause of cough with reflux and chest pain, without improvement on PPIs other causes should be evaluated. His lack of improvement on a PPI excluded GERD as the primary concern, and his minimization of dysphagia, and the prolonged nature of the processes, despite inhaled asthma corticosteroids and the steroid injection, suggested a slow evolution of his EoE. The budesonide is considered primary therapy for EoE and was the necessary prolonged therapy of benefit [5]. Whether he actually has (had) asthma is debatable, and longitudinal observation should prove helpful.

The lack of improvement in the cough prior to the initiation of budesonide but after several different PPI trials is consistent with the EoE diagnosis. A PPI may have benefit as partial EOE medical management, but rarely provides complete benefit. Currently, in pediatric EoE management, a $\mathrm{pH}$ probe assessment of GERD prior to a EGD is extremely uncommon. Elements of our decisions on his EoE care are discussed in the AGREE conference proceedings [12].

The strength of this case is that most of the care of this patient happened within our facility, so cross-communication between specialists was strong, and this helped us diagnose his EoE despite an uncommon presentation. Another strength to this case is that his history of GERD not successfully treated with a proton pump inhibitor (PPI) was helpful (after the visit to the allergist) in initiating diagnostic evaluation esophagogastroduodenoscopy (EGD). A limitation to this case is that several appointments had to be conducted via Telehealth due to the distance from our clinic and scheduling limitations due to existing COVID precautions. His conflicting asthma diagnosis also delayed the diagnosis. The ability to eventually stop asthma therapy further highlights the complexity of the case, but also the rarity with which EoE presents predominantly with a cough.

Author Contributions: Conceptualization, V.S., R.H. and A.D.; writing-original draft preparation, V.S.; writing-review and editing, R.H. and V.S.; visualization, A.D.; supervision, H.N. All authors have read and agreed to the published version of the manuscript.

Funding: This research received no external funding.

Institutional Review Board Statement: Ethical review and approval were waived for this study, because it is a clinical report.

Informed Consent Statement: Written informed consent has been obtained from the patients to publish this paper.

Conflicts of Interest: The authors declare no conflict of interest.

\section{References}

1. Ma, C.; Schoepfer, A.M.; Safroneeva, E.; Dellon, E.S.; Bredenoord, A.J.; Chehade, M.; Collins, M.H.; Feagan, B.G.; Furuta, G.T.; Gupta, S.K.; et al. Development of a Core Outcome Set for Therapeutic Studies in Eosinophilic Esophagitis (COREOS): An International Multidisciplinary Consensus. Gastroenterology 2021, 161, 748-755. [CrossRef] [PubMed]

2. Reed, C.C.; Dellon, E.S. Eosinophilic esophagitis. Med. Clin. N. Am. 2019, 103, 29-42. [CrossRef] [PubMed]

3. Muir, A.; Moore, H.; Spergel, J. To treat or not to treat: The minimally symptomatic EoE patient. Ann. Allergy Asthma Immunol. 2019, 122, 572-573. [CrossRef] [PubMed]

4. Chehade, M.; Nowak-Wegrzyn, A. The asymptomatic patient with eosinophilic esophagitis: To treat or not to treat? Ann. Allergy Asthma Immunol. 2019, 122, 550-551. [CrossRef] [PubMed]

5. Lehman, H.K.; Lam, W. Eosinophilic Esophagitis. Pediatr. Clin. N. Am. 2019, 66, 955-965. [CrossRef] [PubMed]

6. Benich, J.J., III; Carek, P.J. Evaluation of the Patient with Chronic Cough. Am. Fam. Physician 2011, 84, 887-892. [PubMed]

7. Chow, P.; Ng, D.K.K. Chronic Cough in Children. Singap. Med. J. 2004, 45, 462-469. [CrossRef]

8. Orizio, P.; Cinquini, M.; Minetti, S.; Alberti, D.; Di Paolo, C.; Villanacci, V.; Torri, F.; Crispino, P.; Facchetti, S.; Rizzini, F.L.; et al Chronic Cough and Eosinophilic Esophagitis: An Uncommon Association. Case Rep. Gastroenterol. 2011, 5, 497-501. [CrossRef] [PubMed] 
9. Hruz, P. Epidemiology of Eosinophilic Esophagitis. Dig. Dis. 2014, 32, 40-47. [CrossRef] [PubMed]

10. Philpott, H.; Nandurkar, S.; Royce, S.G.; Thien, F.; Gibson, P.R. Risk factors for eosinophilic esophagitis. Clin. Exp. Allergy 2014, 44, 1012-1019. [CrossRef] [PubMed]

11. Capucilli, P.; Hill, D.A. Allergic Comorbidity in Eosinophilic Esophagitis: Mechanistic Relevance and Clinical Implications. Clin. Rev. Allergy Immunol. 2019, 57, 111-127. [CrossRef] [PubMed]

12. Dellon, E.S.; Liacouras, C.A.; Molina-Infante, J.; Furuta, G.T.; Spergel, J.M.; Zevit, N.; Spechler, S.J.; Attwood, S.E.; Straumann, A.; Aceves, S.S.; et al. Updated International Consensus Diagnostic Criteria for Eosinophilic Esophagitis: Proceedings of the AGREE Conference. Gastroenterology 2018, 155, 1022-1033.e10. [CrossRef] [PubMed] 